\title{
Does expanded artificial intelligence improve the prognostic value of myocardial perfusion imaging? A report from the NHLBl-sponsored women's ischemia syndrome evaluation (WISE)
}

\author{
Mark Doyle ${ }^{1 *}$, Gerald M Pohost ${ }^{2}$, Leslee J Shaw ${ }^{3}$, Diane A Vido ${ }^{1}$, Sheryl F Kelsey ${ }^{6}$, BD Johnson ${ }^{6}$, William J Rogers ${ }^{4}$, \\ Geetha Rayarao', Barry L Sharaf ${ }^{5}$, Carl J Pepine ${ }^{7}$, Noel B Merz ${ }^{8}$, Robert W Biederman ${ }^{1}$
}

From 16th Annual SCMR Scientific Sessions

San Francisco, CA, USA. 31 January - 3 February 2013

\section{Background}

We previously introduced a model-based approach (Decisions Informed by Computed Entities [DICE]), a mathematical form of Artificial Intelligence (AI) to improve prognostic values of quantitative myocardial perfusion imaging (MPI). When DICE was applied to cardiovascular MRI (CMR) it improved prediction of MACE in women with suspected ischemic heart disease (IHD) compared to the conventional MPI interpretation. Our aim is to determine if expanded DICE modeling improves prognostic capability to predict MACE.

\section{Methods}

Women $(\mathrm{n}=228)$, mean age $59 \pm 11$ yrs, with suspected myocardial ischemia underwent MPI and cardiac function evaluation separately by CMR and SPECT. Primary endpoint: MACE defined as cardiovascular death, MI, and hospitalization for CHF. The MPI test and 3 comorbidities were assessed: diabetes (DM), hypertension (HTN), and inadequate stress (IS) during MPI testing. The prognostic value of each variable on overall survival was studied separately and in combination using Kaplan-Meier curves with $\log$-rank tests. Boolean logic was used to determine final disease severity category $(0-2)$.

\section{Results}

Results During FU of 40+16mo, 22 women (10\%) had MACE. The log-rank statistic for MACE prediction for MPI was $9(\mathrm{p}<0.005)$, for HTN was $12(\mathrm{p}<0.001)$, for DM

${ }^{1}$ Cardiac MRI, Allegheny General Hospital, Pittsburgh, PA, USA

Full list of author information is available at the end of the article was $5(\mathrm{p}<0.05)$, and for IS was $2(\mathrm{p}=0.2)$. Combining MPI and HTN demonstrated the strongest prognostic value for predicting MACE (log-rank statistic 26, $\mathrm{p}<0.001$ ) with $95 \%$ survival in pts without detectable disease vs. 70\% survival in pts with positive MPI and HTN. Combining DM and IS provided further prognostic value in the MPI and HTN positive group with survival rates of $79 \%$ and $40 \%(\mathrm{p}<0.05)$. For MPI, HTN, DM and IS, positive test results were assigned a 1 and negative results were assigned 0 . Using Boolean logic, when categorizing disease in pts as the sum of (MPI AND HTN) + (DM AND IS) pts had score of 0 (mild), 1 (moderate), or 2 (severe), the Kaplan-Meier log- rank statistic over the three disease severity categories was $42(\mathrm{p}<0.001)$ with actual survival rates of $97 \%, 80 \%$ and $40 \%$ for increasing disease severity.

\section{Conclusions}

Expanded DICE mathematical modeling via AI incorporated with MPI interpretation markedly increases prognostic values of MACE prediction in women with suspected IHD over standard MPI.

\section{Funding}

$\mathrm{NIH}$

\section{Author details \\ ${ }^{1}$ Cardiac MRI, Allegheny General Hospital, Pittsburgh, PA, USA. ${ }^{2}$ University of Southern California, Los Angeles, CA, USA. ${ }^{3}$ Atlanta Cardiovascular Research Inst., Atlanta, GA, USA. ${ }^{4}$ University of Alabama, Birmingham, AL, USA. ${ }^{5}$ Brown University, Providence, RI, USA. ${ }^{6}$ University of Pittsburgh, Pittsburgh, PA, USA. ${ }^{7}$ University of Florida, Gainesville, FL, USA. ${ }^{8}$ Cedars-Sinai Medical Center, Los Angeles, CA, USA.}


Cite this article as: Doyle et al: Does expanded artificial intelligence improve the prognostic value of myocardial perfusion imaging? A report from the NHLBI-sponsored women's ischemia syndrome evaluation (WISE). Journal of Cardiovascular Magnetic Resonance 2013 15(Suppl 1):P273.

Submit your next manuscript to BioMed Central and take full advantage of:

- Convenient online submission

- Thorough peer review

- No space constraints or color figure charges

- Immediate publication on acceptance

- Inclusion in PubMed, CAS, Scopus and Google Scholar

- Research which is freely available for redistribution

Submit your manuscript at www.biomedcentral.com/submit

() Biomed Central 